\title{
Effects of the off-Season Period on Field and Assistant Soccer Referees`Physical Performance
}

\author{
by \\ Daniel Castillo ${ }^{1}$ Jesús Cámara ${ }^{1}$, Carlo Castagna ${ }^{2}$, Javier Yanci ${ }^{1}$
}

\begin{abstract}
The evolution of referees' physical fitness has been studied over one or several seasons, however, the variation of the physical performance between the end of the competitive season (T1) and the start of the following pre-season (T2) has not been ascertained. Therefore, the aim of this study was to analyze the effects of the transition period on physical performance variables (i.e. linear straight sprint, change of direction ability and endurance) in National Soccer Division referees. Forty-five Spanish referees volunteered to participate in this study. Participants were classified according to competitive status, field referees ( $F R, n=23)$ and assistant referees $(A R, n=22)$. A loss of performance $(p<0.05)$ was observed in the 20 and $30 \mathrm{~m}$ linear straight sprint between $T 1$ and $T 2$ in both $F R(1.64-1.56 \%, d=0.29$ to 0.32$)$ and $A R(2.01-3.41 \%, d=0.33$ to 0.60$)$. In T2 the FR significantly improved the distance covered $(p<0.05,13.11 \%, d=$ 0.39) in the Yo-Yo Intermittent Recovery test (YYIR1). Besides, significant differences were observed between FR and $A R$ in the distance covered $(p<0.05,-23.55 \%, d=-0.97)$ in the YYIR1 test in T2. More research may be necessary to focus on the off-season period in order to implement specific training programs and consequently reduce the loss of sprint ability in field and assistant referees and the decrease in cardiovascular fitness in assistant referees.
\end{abstract}

Key words: detraining, acceleration, change of direction, endurance, physical fitness, soccer.

\section{Introduction}

The off-season period (i.e. transition period) has taken a relevant role across the soccer's world. Considering the growing economic importance of soccer competitions and the increase of the number of matches around the world (regardless of the competitive-level), soccer referees have been involved in officiating during most of the year (Da Silva et al., 2011). Subsequently, the transition period is shorter and soccer referees have only few weeks to prepare to the competitive season. Given that refereeing is a very demanding activity both physically and physiologically (Mallo et al., 2008), soccer referees must ensure a high level of physical fitness. Indeed, field referees (FR) were reported to cover a total distance of 10-12 km (Krustrup and
Bangsbo, 2001; Weston et al., 2007) and assistant referees (AR) of 6-8 $\mathrm{km}$ during competitive matches (Krustrup et al., 2002; Mallo et al., 2008). Furthermore, FR and AR may perform as much as 1,269 and 1,053 activity changes during a match, respectively, with FR undertaking 21.3-30.5 sprints at a speed above $25.2 \mathrm{~km} \cdot \mathrm{h}-1$ (Krustrup and Bangsbo, 2001), whereas AR run up to 20 sprints per match (Krustrup et al., 2002). Given that match officials must be physically fit to keep up with the game tempo to make appropriate decisions (Weston et al., 2012), referees international and national governing boards require the evaluation of FR and AR's physical fitness at the start of the competitive season with the pass of set limits to be included in the seasonal

1 - Faculty of Education and Sport, University of the Basque Country, UPV/EHU, Vitoria-Gasteiz, Spain.

2 - Football Training and Biomechanics Laboratory, Italian Football Federation (FIGC), Technical Department, Coverciano

(Florence), Italy. 
match appointment list.

As a result, the seasonal evolution of the physical fitness of match officials is currently considered as a key methodological issue in modern soccer (Castagna et al., 2007; Weston et al., 2012). Despite this, only few studies have examined seasonal variations in physical performance of elite level FRs with no research report addressing AR (Weston et al., 2004, 2011). Furthermore, no study has focused on the training transition period or the part of the season that spans from the end of the previous competitive season to the new one. Considering that there is no information regarding the physical fitness of elite level match officials during the off-season period, a better understanding of the evolution of their physical fitness during this period would help adjust their training programs.

Therefore, it would be interesting to determine the effects of this transition period on FR and AR's physical performance. In soccer, several studies focused on the off-season period (Miller et al., 2011; Moore et al., 2005) with contradictory results. Indeed, Miller et al. (2011) observed that soccer players maintained a relatively high fitness level, while other researchers (Amigo et al., 1998; Caldwell and Peters, 2009) reported a loss of physical performance during the off-season period. As a result, no direct evidence is currently available on how to conduct an effective transition trainingperiod in soccer players and match officials.

Therefore, the aim of this study was to analyze the effects of the transition period (i.e. June to August) on physical performance variables (i.e. linear straight sprint, change of direction ability and endurance) in National Soccer Division referees.

\section{Material and Methods}

\section{Participants}

Forty-five Spanish soccer referees (29.6 \pm $7.8 \mathrm{yr}, 73.3 \pm 7.6 \mathrm{~kg}, 175.9 \pm 5.6 \mathrm{~cm}$ and $23.7 \pm 2.1$ $\mathrm{kg} \cdot \mathrm{m}^{-2}$ ) that officiated during official soccer matches of the Spanish National Division during the 2014/2015 season volunteered to participate in this study. They had at least 6 years of refereeing experience at this level of competition. Participants were classified according to competitive status, FR $(\mathrm{n}=23,30.0 \pm 6.7 \mathrm{yr}, 73.3 \pm$ $8.1 \mathrm{~kg}, 176.8 \pm 6.1 \mathrm{~cm}$ and $\left.23.4 \pm 1.8 \mathrm{~kg} \cdot \mathrm{m}^{-2}\right)$ and
AR $(\mathrm{n}=22,29.2 \pm 8.9 \mathrm{yr}, 73.3 \pm 7.3 \mathrm{~kg}, 175.0 \pm 5.6$ $\mathrm{cm}$ and $23.9 \pm 2.3 \mathrm{~kg} \cdot \mathrm{m}^{-2}$ ). The study was performed in accordance with the Declaration of Helsinki (2013), was approved by the University of the Basque Country (UPV/EHU) Ethics Committee and met the ethical standards in Sport and Exercise Science Research.

\section{Procedures}

The study was designed to determine the effects of a 9 week off-season period on the results of relevant fitness tests evaluating linear sprint, change of direction and intermittent highintensity performance in FR and AR (Castagna et al., 2007, 2012; Weston et al., 2012). Tests were performed at the end of the season (T1, in June) and at the start of the pre-season (T2, in August) at the same venue. During the off-season period, soccer referees trained following the recommendations designed by a professional in Sports Sciences who worked as a personal trainer for the Spanish Committee of Soccer Referees during the competitive season. The training program recommended three weeks of low intensity activities (i.e. walking or cycling) followed by five more weeks focusing on low intensity running (under $70 \%$ of the individual maximum heart rate, $H R_{\max }$ ) and exercise, (i.e. paddle or swimming). Neither strength activities nor sprint tasks were considered for the offseason period. Tests were preceded by a standard warm-up consisting of $7 \mathrm{~min}$ of slow jogging, followed by progressive sprints and static stretching. Referees undertook, in this order, a 30$\mathrm{m}$ straight sprinting test, a modified agility T-test (MATF) and the Yo-Yo intermittent recovery level 1 test (YYIR1). The linear straight sprint and the MATF were interspersed with $4 \mathrm{~min}$ of semiactive rest. Eight minutes of standardised recovery for all participants were allowed between the MATF and the YYIR1.

Performance tests

Linear straight sprinting test: Each referee performed an acceleration test consisting of three maximal sprints of $30 \mathrm{~m}$ length (Krustrup et al., 2002), with a $90 \mathrm{~s}$ rest period between each sprint. Participants were asked to place themselves $0.5 \mathrm{~m}$ from the starting point and began when they felt ready. Split time at $20 \mathrm{~m}$ and the time to cover the $30 \mathrm{~m}$ were measured. Time was recorded using photocell gates (Microgate ${ }^{\mathrm{TM}}$ Polifemo, Bolzano, Italy). 
Modified agility test free (MATF): The referees completed the protocol by Yanci et al. (2014). All participants performed the test three times with at least three minutes of rest between trials. The total distance covered was $20 \mathrm{~m}$. A photocell (Microgate ${ }^{\mathrm{TM}}$ Polifemo, Bolzano, Italy) was used to record the time. Participants were asked to begin $0.5 \mathrm{~m}$ behind the starting line (point A, Figure 1) and sprint forward as fast as possible, touching with one hand and in this order the top of cone B, C, D and B, and finally return to line A.

Yo-Yo intermittent recovery level 1 test (YYIR1): The YYIR1 consisted of $2 \times 20 \mathrm{~m}$ runs back and forth between two lines at a progressively increasing speed controlled by audio beeps. When the participants twice failed to reach the corresponding line in time, the distance covered was recorded and represented the test result. Each bout was interspersed with a $10 \mathrm{~s}$ active rest period consisting of $2 \times 5 \mathrm{~m}$ of jogging. During the test, the heart rate (HR) was recorded every $1 \mathrm{~s}$ using the Polar Team System (Polar ${ }^{\mathrm{TM}}$ Electro Oy, Kempele, Finland). The individual maximum $\mathrm{HR}\left(\mathrm{HR}_{\max }\right)$ was determined as the peak value reached during the test. At the end of the test the data were downloaded to a computer and processed using Polar Precision 2.0 software (Polar ${ }^{\mathrm{TM}}$, Kempele, Finland). One minute after finishing the YYIR1, tympanic temperature (ThermoScan $^{\mathrm{TM}} 5$ IRT 4520, Braun GmbH, Krongerg, Germany) was measured (Hamilton et al., 2013). The 0-10-point scale (Foster et al., 2001) of the respiratory rate of perceived exertion (RPEres) (Green et al., 2009) and the leg muscular rate of perceived exertion (RPEmus) (Los Arcos et al., 2014) were used to determine the subjective perception of fatigue. $\mathrm{VO}_{2 \max }$ was estimated from the following equation: $\mathrm{VO}_{2 \max }\left(\mathrm{ml} \cdot \mathrm{min}^{-1} \cdot \mathrm{kg}^{-1}\right)=$ YYIR1 distance $(\mathrm{m}) \times 0.0084+36.4$ (Bangsbo et al., 2008).

\section{Statistical analysis}

Results are presented as means \pm standard deviations (SD). Normal distribution was tested using the Kolmogorov-Smirnov test and statistical parametric techniques were applied. A $t$ test for paired samples was used to analyze the differences between the end of the season (T1) and the start of the preseason (T2) independently for each group (FR, AR and total sample). Both in $\mathrm{T} 1$ and T2, a paired t-test for independent samples was used to compare results between FR and AR. The in-between groups (FR and AR) comparison from $\mathrm{T} 1$ to $\mathrm{T} 2$ was performed by two way mixed ANOVA (group $x$ time). Practical significance was assessed by calculating Cohen's d effect size. Effect sizes (d) of above 0.8 , between 0.8 and 0.5 , between 0.5 and 0.2 and lower than 0.2 were considered as large, moderate, small and trivial, respectively. Differences between means were expressed as percentages. Statistical significance was set at $p<0.05$. Data analysis was performed using the Statistical Package for Social Sciences (version 21.0 for Windows, SPSS Inc, Chicago, IL, USA).

\section{Results}

No significant $(p>0.05, \mathrm{ES}=$ trivial to small) between group differences were detected at $\mathrm{T} 1$ for the $30 \mathrm{~m}$ test and MATF1 (Table 1). Moderate differences between groups $(E S=0.70)$ for the MATF were detected at T2. A pre-to-post loss of performance $(p<0.05)$ was observed in the 20 and 30-m test in FR (+1.64-1.56\%, ES = small) and AR $(+2.01-3.41 \%, E S=$ small to moderate).

Table 2 shows the results of the YYIR1 test for the total sample (FR and AR). The FR significantly improved YYIR1 performance $(+13.11 \%$, ES = small $)$ and $\mathrm{VO}_{2 \max }(+3.71 \%$, ES $=$ small $)$ at $\mathrm{T} 2$. The YYIR1 performance declined in AR $(-3.36 \%$, ES = trivial) at T2. Significant differences were observed in YYIR1 (ES = -0.97, large), $\mathrm{VO}_{2 \max }(-$ $7.27 \%$, ES = large), RPE res $(-15.72 \%$, ES = large $)$ and RPEmus $(-26.47 \%$, ES = large) at T2 between FR and AR.

\section{Discussion}

The aim of this study was to examine the effects of the off-season period (between the end of a competitive season and the start of the following pre-season) on physical performance variables of soccer referees. Physical performance of soccer referees (Casajus and Castagna, 2007; Castagna et al., 2002, 2005; Weston et al., 2009) and the effects of in-season training programs on soccer referees' performance have been previously presented in the literature (Krustrup and Bangsbo, 2001; Weston et al., 2011; YanciIrigoyen, 2014). 


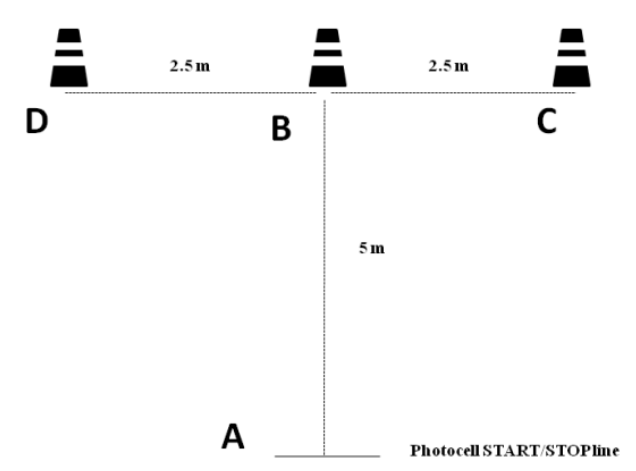

Figure 1

Modified agility T-test free (MATF) design.

Table 1

Straight sprint (20, 30 and 20-30 $\mathrm{m}$ ) and modified agility test free (MATF) results in $T 1$ and $T 2$ for total sample $(n=45)$,

field referees $(F R, n=23)$ and assistant referees $(A R, n=22)$

\begin{tabular}{|c|c|c|c|c|c|}
\hline & Group & $\mathrm{T} 1$ & $\mathrm{~T} 2$ & $\Delta \mathrm{T} 1-\mathrm{T} 2(\%)$ & Cohen d \\
\hline \multirow[t]{5}{*}{ Sprint $20 \mathrm{~m}(\mathrm{~s})$} & Total sample & $3.07 \pm 0.15$ & $3.13 \pm 0.16^{* *}$ & 2.00 & 0.40 \\
\hline & FR & $3.07 \pm 0.16$ & $3.12 \pm 0.17^{*}$ & 1.64 & 0.32 \\
\hline & $\mathrm{AR}$ & $3.04 \pm 0.17$ & $3.14 \pm 0.16^{* *}$ & 3.41 & 0.60 \\
\hline & $\Delta$ FR-AR (\%) & -1.19 & 0.54 & - & - \\
\hline & ES & -0.24 & 0.10 & - & - \\
\hline \multirow[t]{5}{*}{ Sprint $30 \mathrm{~m}$ (s) } & Total sample & $4.31 \pm 0.23$ & $4.37 \pm 0.25^{*}$ & 1.38 & 0.26 \\
\hline & FR & $4.30 \pm 0.23$ & $4.37 \pm 0.27^{*}$ & 1.56 & 0.29 \\
\hline & $\mathrm{AR}$ & $4.27 \pm 0.26$ & $4.35 \pm 0.21^{* *}$ & 2.01 & 0.33 \\
\hline & $\Delta$ FR-AR (\%) & -0.89 & -0.46 & - & - \\
\hline & ES & -0.16 & -0.08 & - & - \\
\hline \multirow{5}{*}{$\begin{array}{l}\text { Sprint } 20-30 \mathrm{~m} \\
\text { (s) }\end{array}$} & Total sample & $1.23 \pm 0.08$ & $1.22 \pm 0.11$ & -1.05 & -0.16 \\
\hline & FR & $1.22 \pm 0.09$ & $1.23 \pm 0.11^{* *}$ & 0.67 & 0.09 \\
\hline & $\mathrm{AR}$ & $1.22 \pm 0.10$ & $1.18 \pm 0.10$ & -3.08 & -0.40 \\
\hline & $\Delta$ FR-AR (\%) & 0.05 & -3.68 & - & - \\
\hline & ES & 0.01 & -0.42 & - & - \\
\hline \multirow[t]{5}{*}{ MATF (s) } & Total sample & $5.49 \pm 0.35$ & $5.46 \pm 0.30$ & -0.45 & -0.07 \\
\hline & FR & $5.55 \pm 0.39$ & $5.54 \pm 0.32$ & -0.08 & -0.01 \\
\hline & $\mathrm{AR}$ & $5.45 \pm 0.37$ & $5.32 \pm 0.20$ & -2.47 & -0.37 \\
\hline & $\Delta$ FR-AR (\%) & -1.73 & -4.08 & - & - \\
\hline & ES & -0.25 & -0.70 & - & - \\
\hline
\end{tabular}

T1 = test 1 , end of the season; $T 2$ = test 2 , beginning of the next season.

Significant differences $\left({ }^{*} p<0.05,{ }^{* *} p<0.01\right)$ between T1 and T2. ES $=$ effect size. 
Table 2

Yo-Yo Intermittent recovery level 1 test (YYIR1) results in $T 1$ and $\mathrm{T} 2$ for total sample $(n=45)$, field referees $(F R, n=23)$ and assistant referees $(A R, n=22)$

\begin{tabular}{|c|c|c|c|c|c|}
\hline & Group & $\mathrm{T} 1$ & $\mathrm{~T} 2$ & $\Delta \mathrm{T} 1-\mathrm{T} 2(\%)$ & Cohen d \\
\hline \multirow[t]{5}{*}{ Distance $(\mathrm{m})$} & Total sample & $1630.00 \pm 556.99$ & $1805.71 \pm 480.70^{*}$ & 10.78 & 0.32 \\
\hline & FR & $1711.67 \pm 579.77$ & $1936.00 \pm 469.61^{*}$ & 13.11 & 0.39 \\
\hline & $\mathrm{AR}$ & $1531.43 \pm 518.02$ & $1480.00 \pm 350.67 \#$ & -3.36 & -0.10 \\
\hline & $\Delta$ FR-AR (\%) & -10.53 & -23.55 & - & - \\
\hline & ES & -0.31 & -0.97 & - & - \\
\hline \multirow[t]{5}{*}{$\mathrm{VO} 2 \max \left(\mathrm{ml} \cdot \mathrm{kg}^{-1} \cdot \mathrm{min}^{-1}\right)$} & Total sample & $50.09 \pm 4.68$ & $51.57 \pm 4.04^{*}$ & 2.95 & 0.32 \\
\hline & FR & $50.78 \pm 4.87$ & $52.66 \pm 3.94^{*}$ & 3.71 & 0.39 \\
\hline & AR & $49,26 \pm 4,35$ & $48.83 \pm 2.95 \#$ & -0.88 & -0.10 \\
\hline & $\Delta$ FR-AR (\%) & -2.98 & -7.27 & - & - \\
\hline & ES & -0.31 & -0.97 & - & - \\
\hline \multirow{5}{*}{$\begin{array}{l}\text { Tympanic temperature } \\
\left({ }^{\circ} \mathrm{C}\right)\end{array}$} & Total sample & $36.49 \pm 0.81$ & $35.55 \pm 0.63^{* *}$ & -2.57 & -1.16 \\
\hline & FR & $36.58 \pm 0.79$ & $35.59 \pm 0.60^{* *}$ & -2.69 & -1.24 \\
\hline & $\mathrm{AR}$ & $36.39 \pm 0.79$ & $35.46 \pm 0.72^{*}$ & -2.55 & -1.17 \\
\hline & $\Delta \mathrm{FR}-\mathrm{AR}(\%)$ & -0.50 & -0.36 & - & - \\
\hline & ES & -0.23 & -0.21 & - & - \\
\hline \multirow[t]{5}{*}{ RPEres } & Total sample & $7.54 \pm 1.39$ & $7.39 \pm 1.29$ & -1.90 & -0.10 \\
\hline & FR & $7.38 \pm 1.50$ & $7.08 \pm 1.20$ & -4.07 & -0.20 \\
\hline & AR & $7.71 \pm 1.07$ & $8.19 \pm 1.25 \#$ & 6.13 & 0.44 \\
\hline & $\Delta$ FR-AR (\%) & 4.60 & 15.72 & - & - \\
\hline & ES & 0.23 & 0.93 & - & - \\
\hline \multirow[t]{5}{*}{ RPEmus } & Total sample & $6.54 \pm 1.97$ & $6.29 \pm 1.70$ & -3.83 & -0.13 \\
\hline & FR & $6.35 \pm 1.86$ & $6.80 \pm 1.32$ & 7.02 & 0.24 \\
\hline & $\mathrm{AR}$ & $6.21 \pm 1.57$ & $5.00 \pm 1.95^{* \# \# ~}$ & -19.54 & -0.77 \\
\hline & $\Delta$ FR-AR (\%) & -2.20 & -26.47 & - & - \\
\hline & ES & -0.08 & -1.36 & - & - \\
\hline \multirow[t]{5}{*}{$\mathrm{HR \operatorname {max }}\left(\mathrm{bt} \cdot \mathrm{min}^{-1}\right)$} & Total sample & $186.37 \pm 11.57$ & $184.15 \pm 6.70$ & -1.19 & -0.19 \\
\hline & FR & $186.57 \pm 12.84$ & $182.70 \pm 6.20$ & -2.08 & -0.30 \\
\hline & $\mathrm{AR}$ & $187.05 \pm 8.10$ & $186.63 \pm 7.82$ & -0.23 & -0.05 \\
\hline & $\Delta$ FR-AR (\%) & 0.26 & 2.15 & - & - \\
\hline & ES & 0.04 & 0.63 & - & - \\
\hline
\end{tabular}

$T 1=$ test 1 , end of season; $T 2=$ test 2 , beginning of the next season;

$V O_{2 m a x}=$ estimated maximal oxygen consumption, $R P E_{\text {res }}=$ respiratory perceived exertion;

$R P E_{m u s}=$ muscular perceived exertion; $H R_{\max }=$ maximal heart rate .

Significant differences $\left({ }^{*} p<0.05,{ }^{* *} p<0.01\right)$ between T1 and T2;

Significant differences (\# $p<0.05, \# p<0.01$ ) between FR and AR. ES $=$ effect size.

However, to our knowledge, this is the first study in which the effects of the off-season period (i.e. June to August) have been analyzed in soccer referees. This study results showed a decrement of straight sprint performance in both the FR and AR after the off- 
season period. Interestingly intermittent highintensity performance measured by the Yo-Yo intermittent recovery test (level 1) increased in FR with mainly practical (trivial decrement) maintenance of performance in AR.

In the present study no differences were found between FR and AR at the end of the season or at the start of the following pre-season in linear straight sprinting and the modified agility test. However, we observed a loss of acceleration performance in each group, as noted in the $20 \mathrm{~m}$ sprint split time in T2. Nevertheless, no pre-to-post differences were reported in MATF performance. These results support the occurrence of a de-conditioning effect in sprint performance during the off-season already documented in semi-professional soccer players (Caldwell and Peters, 2009). This may have been partly the result of the lack of strength exercises to maintain power of the lower limbs considered in the provided post-season training guideline. It would be interesting to study whether this loss of performance could be affected by detraining of the fast twitch muscle fibers of both, FR and AR. The evidence of an increase or maintenance of YYIR1 performance in T2 may suggest a polarisation of training specificity over endurance sessions particularly in FR. Interestingly, the fact that a loss of performance in the modified agility test free was not found in the present study, could be due to the coordinative cognitive components such as visual-scanning techniques, visualscanning speed and anticipation that may affect change of direction ability (Sheppard and Young, 2006). Given the interest of the issue, further studies considering detailed training-log monitoring during the transition period in AR and FR are warranted. This would be of particular interest for AR as repeated sprint ability was reported to be related with match physical performance in elite ARs (Krustrup et al., 2002).

Although no differences were found in any of the variables in T1, FR registered better results than AR in the MATF (ES = 0.70, $p>0.05$ ), in YYIR1 performance ( $E S=0.97, p<0.05)$ and $\mathrm{VO} 2 \max (\mathrm{ES}=0.97, \mathrm{p}<0.05)$ at T2. Furthermore, despite a higher reported RPEres score in AR, RPEmus values were lower than that for FR in $T 2$. Only FR showed significantly better results in the distance covered and VO2max in the Yo-Yo intermittent recovery test (level 1) after the offseason period. Therefore, while FR improved their cardiovascular performance, AR tended to obtain worse results in the Yo-Yo intermittent recovery test (level 1). It would be interesting to implement specific endurance programs especially in AR during this period in order to not decrease the resistance capacity during the off-season period.

Match officials in soccer have to possess an optimum level of physical fitness at the start of the competitive season to warrant their eligibility to be appointed for championship matches and for this reason during the transition period soccer referees do not stop their physical training completely. The physical requisites of the resistance capacity test (ie. 150-50) are higher for FR than for AR. Even though both FR and AR must complete 20 intervals consisting of $150 \mathrm{~m}$ running in $30 \mathrm{~s}$, the former have a recovery time of $30 \mathrm{~s}$ to walk $50 \mathrm{~m}$, whilst for the latter, the recovery time is longer (16.6\%) (Mallo et al., 2009). It is likely that FR had trained their cardiovascular capacity more during the off-season because generally they are responsible for making key decisions to ensure the proper course of the game and consequently they are required to keep up with the play at the start of the competitive season. However, AR do not need such rigorous physical preparation to develop their refereeing activity in competition.

We could conclude that soccer referees decreased acceleration capacity after 9 weeks of the off-season period, suggesting that it would be interesting to analyze whether specific training programs would compensate for this loss of acceleration performance. It could be speculated that implementing specific lower-limb power training throughout the transition period could compensate the loss of acceleration performance in FR and AR. Furthermore, AR transition training should focus more on endurance training and/or consider more specific testing of endurance (Castagna et al., 2012). Given that a strong relationship has been observed between physical performance and match activity (Weston et al., 2009), this study provides coaches with information useful to guide match official preparation during the off-season. 


\section{Acknowledgements}

This study was supported by the Department of Education, Linguistic Policies and Culture of the Basque Government as part of the program for Pre-doctoral training for research personnel who are still not doctors corresponding to the 2014-2015 academic year.

The authors would like to thank the participants from the Navarre Committee of Football Referees (Comité Navarro de Árbitros de Fútbol).

\section{References}

Amigo N, Cadefau JA, Ferrer I, Terrados N, Cusso R. Effect of summer intermission on skeletal muscle of adolescent soccer players. J Sports Med Phys Fitness, 1998; 38: 298-304

Bangsbo J, Iaia F, Krustrup P. The Yo-Yo intermittent recovery test - A useful tool for evaluation of physical performance in intermittent sports. Sports Med, 2008; 38: 37-51

Caldwell BP, Peters DM. Seasonal variation in physiological fitness of a semiprofessional soccer team. $J$ Strength Cond Res, 2009; 23: 1370-1377

Casajus JA, Castagna C. Aerobic fitness and field test performance in elite Spanish soccer referees of different ages. J Sci Med Sport, 2007; 10: 382-389

Castagna C, Abt G, D'Ottavio S. Physiological aspects of soccer refereeing performance and training. Sports Med, 2007; 37: 625-646

Castagna C, Abt G, D'Ottavio S, Weston M. Age-related effects on fitness performance in elite-level soccer referees. J Strength Cond Res, 2005; 19: 785-790

Castagna C, Abt G, D'Ottavio E. The relationship between selected blood lactate thresholds and match Performance in elite soccer referees. J Strength Cond Res, 2002; 16: 623-627

Castagna C, Bendiksen M, Impellizzeri FM, Krustrup P. Reliability, sensitivity and validity of the assistant referee intermittent endurance test (ARIET) - a modified Yo-Yo IE2 test for elite soccer assistant referees. J Sports Sci, 2012; 30(8): 767-775

Da Silva AI, Fernandes LC, Fernandez R. Time motion analysis of football (soccer) referees during official matches in relation to the type of fluid consumed. Braz J Med Biol Res, 2011; 44(8): 801-809.

Foster C, Florhaug JA, Franklin J, Gottschall L, Hrovatin LA, Parker S, Doleshal P, Dodge C. A new approach to monitoring exercise training. J Strength Cond Res, 2001; 15: 109-115

Green JM, McIntosh JR, Hornsby J, Timme L, Gover L, Mayes JL. Effect of exercise duration on session RPE at an individualized constant workload. Eur J Appl Physiol, 2009; 107: 501-507

Hamilton PA, Marcos LS, Secic M. Performance of infrared ear and forehead thermometers: a comparative study in 205 febrile and afebrile children. J Clinic Nurs, 2013; 22: 2509-2518

Krustrup P, Bangsbo J. Physiological demands of top-class soccer refereeing in relation to physical capacity: effect of intense intermittent exercise training. J Sports Sci, 2001; 19: 881-891

Krustrup P, Mohr M, Bangsbo J. Activity profile and physiological demands of top-class soccer assistant refereeing in relation to training status. J Sports Sci, 2002; 20: 861-871

Los Arcos A, Yanci J, Mendiguchia J, Gorostiaga EM. Rating of muscular and respiratory perceived exertion in professional soccer players. J Strength Cond Res, 2014; 28: 3280-3288

Mallo J, Navarro E, Garcia-Aranda JM, Gilis B, Helsen W. Analysis of the kinematical demands imposed on top-class assistant referees during competitive soccer matches. J Strength Cond Res, 2008; 22: 235-242

Mallo J, Navarro E, García-Aranda JM, Helsen W. Activity profile of top-class association football referees in relation to fitness-test performance and match standard. J Sports Sci, 2009; 27(1): 9-17

Miller DK, Kieffer HS, Kemp HE, Torres SE. Off-season physiological profiles of elite National Collegiate 
Athletic Association Division III male soccer players. J Strength Cond Res, 2011; 25: 1508-1513

Moore EW, Hickey MS, Reiser RF. Comparison of two twelve week off-season combined training programs on entry level collegiate soccer players' performance. J Strength Cond Res, 2005; 19: 791-798

Sheppard JM, Young WB. Agility literature review: classifications, training and testing. J Sports Sci, 2006; 24: 919-932

Weston M, Castagna C, Helsen W, Impellizzeri F. Relationships among field-test measures and physical match performance in elite-standard soccer referees. J Sports Sci, 2009; 27: 1177-1184

Weston M, Castagna C, Impellizzeri FM, Rampinini E, Abt G. Analysis of physical match performance in English Premier League soccer referees with particular reference to first half and player work rates. J Sci Med Sport, 2007; 10: 390-397

Weston M, Castagna C, Impellizzeri FM, Bizzini M, Williams AM, Gregson W. Science and medicine applied to soccer refereeing. An update. Sports Med, 2012; 42(7): 615-631.

Weston M, Gregson W, Castagna C, Breivik S, Impellizzeri FM, Lovell RJ. Changes in a top-level soccer referee's training, match activities, and physiology over an 8-year period: A case study. Int J Sports Physiol Perform, 2011; 6: 281-286

Weston M, Helsen W, MacMahon C, Kirkendall D. The impact of specific high-intensity training sessions on football referees' fitness levels. American J Sports Med, 2004; 32(1 Suppl): 54-61

Yanci J, Los Arcos A, Mendiguchia J, Brughelli M. Relationships between sprinting, agility, one and two leg vertical and horizontal jump ability in soccer players. Kinesiol, 2014; 46: 194-201

Yanci-Irigoyen J. Changes in the physical fitness of soccer referees: a longitudinal study. Int J Sports Sci, 2014; $10 ; 336-345$

\section{Corresponding author:}

\section{Daniel Castillo}

Faculty of Education and Sport, University of the Basque Country, UPV/EHU,

Lasarte, 71, 01007. Vitoria-Gasteiz, Spain.

Telephone: 945013565

E-mail: daniel.castillo@ehu.es 